\title{
Periprocedural Plasma Fibrinogen level and Clinical Outcome of Coronary Stent Implantation
}

\author{
SHEIKH MOHAMMAD SAMSUZZAMAN ${ }^{1}$, MD. FAKHRUL ISLAM KHALED ${ }^{2}$, SAYED MAINUDDINAHMED $^{3}$, \\ MD.AL-AMIN ${ }^{4}$, RAKIBUL RASHED ${ }^{5}$, MD. ZAINALABEDIN ${ }^{6}$, HOSSAIN MUHAMMAD MUSTAFIJUR RAHMAN ${ }^{7}$, \\ MOHAMMAD ANWARUL BARI ${ }^{1}$, MD.AZHARUL ISLAM ${ }^{2}$, MD. HARISUL HOQUE ${ }^{2}$, \\ MD ABU SELIM², SM MUSTAFAZAMAN²,
}

${ }^{1}$ Department of Medicine, Sir Salimullah Medical College, Dhaka, ${ }^{2}$ Department of Cardiology, Bangbandhu Sheikh Mujib Medical University. (BSMMU) Dhaka, ${ }^{3}$ Juniour Consultant, Gopalgonj Sadar Hospital, Gopalgonj ${ }^{4}$ Department of Cardiology, , National Institute of Cardiovascular Diseases \& Hospital (NICVD), Dhaka, ${ }^{5}$ Department pf Cardiology, Rajshahi Medical College, Rajshahi, ${ }^{6}$ Hypertension \& Research Center, Dhap, Rangpur, ${ }^{7}$ Department of Nephrology, Dhaka Medical College Hospital (DMCH), Dhaka,

Address of Correspondence: Sheikh Mohammad Samsuzzaman, Asssiatnt Professor (Medicine), Sir Salimullah Medical College, Dhaka,E mail - smsamsuzzaman@gmail.com

\begin{abstract}
:
Coronary artery disease (CAD) is the leading cause of mortality and morbidity both in developed and developing countries. Percutaneous recanalization of occluded coronary artery is one of the treatment options and reinfarction and restenosis negatively affect the outcome following procedure. Although various factors including fibrinogen are suspected as risk factors for this but its role in adverse outcome after stent implantation is controversial. The aim of this study was to determine the impact \& relation of periprocedural fibrinogen level on outcome after coronary stent implantation. This prospective study was conducted in the Department of Cardiology, University Cardiac Centre, Bangabandhu Sheikh Mujib Medical University (BSMMU), Hospital, Dhaka over a period of one year between July 2016 to June 2017. Total 53 patients of chronic stable angina (CSA) undergoing elective PTCA followed by stenting were included in this study as per inclusion and exclusion criteria. Plasma fibrinogen level was measured by collecting venous blood samples at three timed points in relation to stenting-24 $h$ before, $24 \mathrm{~h}$ after and $72 \mathrm{~h}$ after stenting. Recurrence of angina, myocardial infarction, repeat revascularization (either PCI or Cardiac surgery), and death were considered as adverse outcome during follow up at 1, 3 and 6 months after intervention. During the 6 months follow up period 1 (one) patient developed UA (at 1 month), 2 developed MI (1 at 3 month and 1 at 6 month) and 2 died (1 at 3 month and 1 at 6 month). Patients were grouped on the basis of four outcomes: favorable outcome (those who did not develop any of the four outcomes) and unfavorable or adverse outcome (those who developed any of the four outcomes).

The mean age of study population was 53.92 years and 39 (73.6\%) were male. Regarding cardiovascular risk factors, $43.4 \%$ patients had diabetes mellitus, $88.6 \%$ had dyslipidaemia, $56.6 \%$ were non-smokers. Baseline plasma fibrinogen level were significantly higher in patients who developed complications following PCI than those who did not develop the complications $(394.4 \pm 16.0 \mathrm{Vs} 271.5 \pm 21.8 \mathrm{mg} / \mathrm{dl})$ \& remained high after 24 hours and 72 hours following PCI $(p<0.001)$. Angiographic profiles of the study population reveals $84.9 \%$ LAD, $16.9 \%$ RCA \& $15 \%$ LCX involvement but there was no association of post-PCI adverse outcomes with vessels involved, number of stents deployed and types of stents used $(p>0.05)$. Study showed that the risk of developing unfavorable outcome following PCI in patients with pre-PCI \& post-PCI high serum fibrinogen was estimated to be 5.7 times \& 12 times higher than those who have had serum fibrinogen lower than $350 \mathrm{mg} /$ dl respectively $(p=0.023 \& 0.025$ respectively). High serum fibrinogen can therefore be used as a marker for predicting adverse outcome following $P C I$.
\end{abstract}

Key words: Stable angina, fibrinogen, percutaneous coronary intervention, adverse outcome following PCI.

University Heart Journal 2021; 17(2): 122-127

Introduction:

Coronary heart disease (CHD) represents a major cause of morbidity and mortality in the world today. Percutaneous coronary intervention (PCI) has become the commonly used treatment of symptomatic coronary artery disease with high success rate. Various factors are shown to affect the outcome of stenting in a patient. Important drawback of PCI is development of in-stent restenosis. ${ }^{1}$ Early elastic 
recoil, late vessel remodeling, and neointimal proliferation have been proposed as important contributors to the restenosis after coronary angioplasty. ${ }^{2}$

The association between inflammation and atherosclerosis has been confirmed and plasma fibrinogen, acute phase reactant protein and a pro-inflammatory marker are significantly increased in most patients with $\mathrm{ACS}^{3,4}$ and plays an important role in platelet aggregation, increases plasma viscosity, causes the release of vasoconstrictor mediators and growth factors which leads to fibrin deposits. ${ }^{5}$ Increased fibrinogen causes alterations in fibrin clot structure and this is shown to impair fibrinolysis and increase the risk of cardiovascular events. ${ }^{6}$ Fibrinogen may be considered a risk factor for restenosis because fibrin degradation products stimulate smooth muscle cell outgrowth which is seen in neointimal proliferation leading to restenosis. ${ }^{5,7}$ Fibrinogen affects platelet aggregation and blood coagulation. Also fibrinogen and its metabolites have direct effects on the vascular wall. ${ }^{8,9}$ Several prospective trials revealed that fibrinogen has a strong predictive power, and numerous pathways have been identified through which fibrinogen can promote atherothrombosis, ${ }^{10}$ although much of this knowledge is not yet generally accepted.

Otuska and colleagues ${ }^{11}$ showed that preprocedural fibrinogen level and stent length are the independent predictors of coronary stent outcome. On the contrary, Pascalle and his colleagues ${ }^{5}$ in their GENDER project concluded that there is no association between preprocedural fibrinogen level and target vessel revascularization by coronary stenting.

Since conflicting results were shown by various studies about baseline fibrinogen levels and stent outcome, the present study was conducted with the idea to determine the relation between periprocedural fibrinogen levels and outcome of coronary stent implantation.

\section{Materials \& Methods:}

This prospective study was carried out in the Department of Cardiology, University Cardiac Centre, Bangabandhu Sheikh Mujib Medical University (BSMMU), Hospital, Dhaka over a period of one year between July 2016 to June 2017. Patients of chronic stable angina (CSA) undergoing elective PTCA followed by stenting were included in this study. Patients were excluded on the background of refusal to give consent, acute myocardial infarction, previous PCI or CABG, acute infection, inflammation or sepsis. Total 60 samples were taken but during study period 7 patients were lost to follow up leaving 53 for final analysis. Demographic profiles of the patients were recorded. Necessary laboratory investigations for PCI were done as per hospital protocol. Five $\mathrm{ml}$ of venous blood sample was collected from the patients in a test-tube containing $3.8 \%$ citrate $24 \mathrm{hrs}$ prior to PCI. Two other venous blood samples were collected from the patients after $24 \mathrm{hrs}$ and after $72 \mathrm{hrs}$ of stenting. Plasma fibrinogen was analyzed using Reagent kits from same diagnostics (BSMMU) using same reagent (automated haematology analyzer STA-compact MAX). Coronary stenting was done using either radial or femoral route under local anesthetics. Use of glycoprotein IIb/IIIa receptor inhibitors and type of stent were at discretion of the interventional cardiologist. Patency of the vessel was assessed by angiography just after the procedure was completed and TIMI flow 3 normal blood flow filling coronary bed was achieved. All patients received a loading dose of antiplatelet (Clopidogrel $300 \mathrm{mg}$ or Prasugrel 60 $\mathrm{mg}$ or Ticagrelor $180 \mathrm{mg}$ ) previous night or on the day of intervention. Patients were advised to continue atorvastatin, aspirin and clopidogrel (or prasugrel or ticagrelor) for at least six months and to attend the follow up clinic at 1, 3 and 6 months after intervention. Cardiac related events like myocardial infarction, repeat revascularization (either PCI or Cardiac surgery), recurrence of angina and death were investigated during follow up session and divided into two groups for analysis. Those who did not develop any of the four outcomes (UA, MI, need for revascularization, Death) were considered as having favorable outcome and those who developed any of the four outcomes were considered as having unfavorable or adverse outcome. The statistical analysis was carried out by using computer software SPSS (Statistical Package for Social Sciences) version 16. Continuous variables were expressed as means $\pm \mathrm{SD}$, while categorical variables expressed as frequency and corresponding percentages. Categorical data were compared between groups (patients with favorable and unfavorable outcomes) using Chi-squared $\left(\chi^{2}\right)$ test and Fisher's Exact test. Continuous data were compared between groups (patients with favorable and unfavorable outcomes) using Unpaired t-Test and Repeated measure ANOVA test (F-test). The level of significance was set at 0.05 and $\mathrm{p}<0.05$ was considered significant. Risk was measured as Relative Risk (RR).

\section{Results:}

The present study intended to determine the impact of peri-PCI serum fibrinogen level on post-PCI outcome. The 
outcome was evaluated in terms of unstable angina, myocardial infarction, revascularization needed and death at 1, 3 and 6 months following PCI. During the 6 months follow up period 1 (one) patient developed UA (at 1 month), 2 developed MI ( 1 at 3 month and 1 at 6 month) and 2 died ( 1 at 3 month and 1 at 6 month). Patients were grouped on the basis of four outcomes : favorable outcome (those who did not develop any of the four outcomes) and unfavorable or adverse outcome (those who developed any of the four outcomes).

Mean age of the study subjects who developed adverse outcome (complications) was on an average 1.5 years younger than those who did not develop the adverse outcome $(p=0.683)$. Males were predominant in either group with no significant intergroup difference $(p=0.398)$. Risk factors were not found to be significantly different between patients who developed and who did not develop the adverse outcome in terms of smoking, HTN, DM, obesity \& dyslipidaemia (Table I).

There was no significant difference between the groups with respect to fasting blood sugar and blood sugar 2 hours after breakfast and mean HbA1c $(\%)(\mathrm{p}=0.515, \mathrm{p}=$ 0.594 and $p=0.634$ respectively). Serum total cholesterol, LDL cholesterol and serum triglycerides were raised in both groups of patients who developed and who did not develop the adverse outcome $(p=0.367, p=0.202$ and $p=$
0.218 respectively). Serum creatinine was also similar in distribution between groups $(\mathrm{p}=0.099)$. (Table II)

However, serum fibrinogen levels before 24 hours and after 24 hours and 72 hours were significantly higher in patients who developed complications following PCI than those who did not develop the complications $(p<0.001)$. Both groups of patients demonstrated increase in serum fibrinogen following PCI. (Table III) (Fig. 1)

As angiographic profile was compared between groups none of the angiographic findings were found to be associated with development of complications following PCI. There was no association of post-PCI adverse outcomes with vessels involved, number of stents deployed and types of stents used $(\mathrm{p}>0.05)$ (Table IV).

Sixty percent of the patients who developed unfavorable outcome had $\geq 350 \mathrm{mg} / \mathrm{dl}$ of serum fibrinogen 24 hours pre-PCI as opposed to only $16.7 \%$ of those who did not develop the same outcomes whereas eighty percent of the patients who developed unfavorable outcome had $\geq 350 \mathrm{mg} / \mathrm{dl}$ of serum fibrinogen 24 and 72 hours post-PCI as opposed to only $25 \%$ of those who did not develop the same outcomes. The risk of developing unfavorable outcome following PCI in patients with pre-PCI \& postPCI high serum fibrinogen was estimated to be 5.7 times \& 12 times higher than those who have had serum fibrinogen lower than $350 \mathrm{mg} / \mathrm{dl}$ respectively $(\mathrm{p}=0.023 \& 0.025$ respectively). (Table $\mathrm{V}$ )

Table-I

Demographic variables \& distribution of risk factors among the study population $(n=53)$

\begin{tabular}{|c|c|c|c|}
\hline \multirow[t]{2}{*}{ Variables } & \multicolumn{2}{|c|}{ Outcome } & \multirow[t]{2}{*}{$\mathrm{P}$-value } \\
\hline & $\begin{array}{c}\text { Unfavorable } \\
(\mathrm{n}=5)\end{array}$ & $\begin{array}{c}\text { Favorable } \\
(\mathrm{n}=48)\end{array}$ & \\
\hline Age (years) & $53.2 \pm 5.6$ & $54.7 \pm 8.4$ & $0.683^{\text {ns }}$ \\
\hline Sex & & & $0.398^{\text {ns }}$ \\
\hline Male & $3(60.0)$ & $36(75.0)$ & \\
\hline Female & $2(40.0)$ & $12(25.0)$ & \\
\hline \multicolumn{4}{|l|}{$\operatorname{BMI}\left(\mathrm{kg} / \mathrm{m}^{2}\right)$} \\
\hline Normal BMI & $3(60.0)$ & $36(75.0)$ & $0.398^{\mathrm{ns}}$ \\
\hline Overweight \& obese & $2(40.0)$ & $12(25.0)$ & \\
\hline \multicolumn{4}{|l|}{ Smoking habit } \\
\hline Smoker & $3(60.0)$ & $20(41.7)$ & $0.373^{\text {ns }}$ \\
\hline Non-smoker & $2(40.0)$ & $28(58.3)$ & \\
\hline DM & $3(60.0)$ & $20(41.7)$ & $0.373^{\text {ns }}$ \\
\hline HTN & $1(20.0)$ & $24(50.0)$ & $0.213^{\text {ns }}$ \\
\hline Dyslipidaemia & $3(60.0)$ & $44(91.7)$ & $0.093^{\text {ns }}$ \\
\hline
\end{tabular}


Table-II

Comparison of patients between groups by their laboratory features $(n=53)$

\begin{tabular}{lccc}
\hline Laboratory features & $\begin{array}{c}\text { Outcome } \\
\text { Unfavorable } \\
(\mathrm{n}=5)\end{array}$ & $\begin{array}{c}\text { Favorable } \\
(\mathrm{n}=48)\end{array}$ & P-value \\
\hline Fasting blood sugar (mmol/L) & $6.3 \pm 1.7$ & $7.3 \pm 3.4$ & $0.515^{\mathrm{ns}}$ \\
Blood sugar 2 hrs after breakfast (mmol/L) & $8.4 \pm 2.8$ & $9.7 \pm 5.4$ & $0.594^{\mathrm{ns}}$ \\
HbA1c level (\%) & $6.5 \pm 0.9$ & $6.9 \pm 2.1$ & $0.634^{\mathrm{ns}}$ \\
Lipid profile & & & \\
Serum total cholesterol (mg/dl) & $198.2 \pm 18.5$ & $205.9 \pm 17.1$ & $0.367^{\mathrm{ns}}$ \\
Serum LDL(mg/dl) & $142.4 \pm 28.7$ & $153.5 \pm 24.8$ & $0.202^{\text {ns }}$ \\
Serum HDL(mg/dl) & $36.4 \pm 7.1$ & $32.1 \pm 5.9$ & $0.137^{\mathrm{ns}}$ \\
Serum Tg(mg/dl) & $281.6 \pm 48.9$ & $288.8 \pm 87.3$ & $0.218^{\text {ns }}$ \\
Serum Creatinine $(\mathrm{mg} / \mathrm{dl})$ & $1.1 \pm 0.1$ & $1.0 \pm 0.1$ & $0.099^{\mathrm{ns}}$ \\
\hline
\end{tabular}

\section{Table-III}

Comparison of peri PCI serum fibrinogen levels between patients who developed and who did not develop adverse outcome $(n=53)$

\begin{tabular}{lcccc}
\hline Outcome & \multicolumn{3}{c}{ Serum fibrinogen level $(\mathrm{mg} / \mathrm{dl})$} & P-value \\
& $24 \mathrm{hr}$ before PCI & $24 \mathrm{hr}$ after PCI & $72 \mathrm{hr}$ after PCI & \\
\hline Unfavorable $(\mathrm{n}=5)$ & $394.4 \pm 16.0$ & $425.8 \pm 10.7$ & $427.6 \pm 6.5$ & $<0.001^{\mathrm{s}}$ \\
Favorable $(\mathrm{n}=48)$ & $271.5 \pm 21.8$ & $301.8 \pm 50.8$ & $309.7 \pm 20.9$ & \\
\hline
\end{tabular}

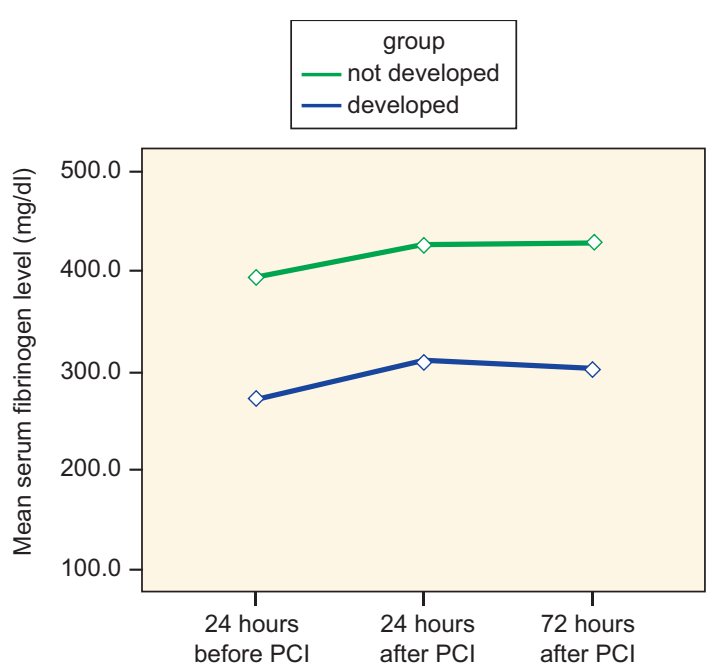

Fig 1: Changes in serum fibrinogen level between patients before and after PCI who developed who did not develop adverse outcome
Table-IV

Comparison of patients by their angiographic profile $(n=53)$

\begin{tabular}{|c|c|c|c|}
\hline \multirow{2}{*}{$\begin{array}{l}\text { Angiographic and } \\
\text { PCI related profile }\end{array}$} & \multicolumn{2}{|c|}{ Outcome } & \multirow[t]{2}{*}{$\overline{P \text {-value }}$} \\
\hline & $\begin{array}{c}\text { Unfavorable } \\
(\mathrm{n}=5)\end{array}$ & $\begin{array}{c}\text { Favorable } \\
(\mathrm{n}=48)\end{array}$ & \\
\hline \multicolumn{4}{|l|}{ Vessels involved } \\
\hline LAD & $5(100.0)$ & $40(83.3)$ & $0.426^{\mathrm{ns}}$ \\
\hline $\mathrm{RCA}$ & $1(20.0)$ & $8(16.7)$ & $0.622^{\mathrm{ns}}$ \\
\hline LCX & $0(0.0)$ & $8(16.7)$ & $0.426^{\mathrm{ns}}$ \\
\hline Number of stents deployed & $1.2 \pm 0.4$ & $1.1 \pm 0.3$ & $0.854^{\mathrm{ns}}$ \\
\hline \multicolumn{4}{|l|}{ Types of stent used } \\
\hline Bare metal & $0(0.0)$ & $12(25.0)$ & \\
\hline Drug eluting & $4(80.0)$ & $32(66.7)$ & $0.364^{\mathrm{ns}}$ \\
\hline Both & $1(20.0)$ & $4(8.3)$ & \\
\hline
\end{tabular}

Figures in the parentheses indicate corresponding \%; 
Table-V

Risk of developing unfavorable outcome due to peri-PCI high fibrinogen level $(n=53)$

\begin{tabular}{llcccc}
\hline Serum fibrinogen level (mg/dl) & \multicolumn{2}{c}{ Outcome } & p - value & $\begin{array}{c}\text { Relative Risk } \\
\text { (95\% CI of RR) }\end{array}$ \\
\cline { 2 - 4 } & & $\begin{array}{c}\text { Unfavorable } \\
(\mathrm{n}=5)\end{array}$ & $\begin{array}{c}\text { Favorable } \\
(\mathrm{n}=48)\end{array}$ & & \\
\hline 24 hours pre-PCI & $\geq 350$ & $3(60.0)$ & $8(16.7)$ & $0.023^{\mathrm{s}}$ & $--5.7(1.1-30.2)^{\mathrm{s}}$ \\
& $<350$ & $2(40.0)$ & $40(83.3)$ & & \\
24 hours post-PCI & $\geq 350$ & $4(80.0)$ & $12(25.0)$ & $0.025^{\mathrm{s}}$ & $12(1.2-118.1)^{\mathrm{s}}$ \\
& $<350$ & $1(20.0)$ & $36(75.0)$ & & \\
72 hours post-PCI & $\geq 350$ & $4(80.0)$ & $12(16.7)$ & $0.025^{\mathrm{s}}$ & $12(1.2-118.1)^{\mathrm{s}}$ \\
& $<350$ & $1(20.0)$ & $36(75.0)$ & & \\
\hline
\end{tabular}

\section{Discussion:}

The present study aimed at determining the peri-PCI plasma fibrinogen level on post-PCI outcomes revealed that $60 \%, 80 \%$ and $80 \%$ of the patients who developed unfavorable outcome had $\geq 350 \mathrm{mg} / \mathrm{dl}$ of serum fibrinogen 24 hours before PCI and 24 hour and 72 hour post PCI respectively as opposed to only $16.7 \%, 25 \%$ and $25 \%$ of those who did not develop the same outcomes. The risk of developing unfavorable outcome in patients with high serum fibrinogen before PCI was nearly 6-times and 12times higher than those who have had serum fibrinogen lower than $350 \mathrm{mg} / \mathrm{dl}$ before PCI $(\mathrm{p}=0.023)$ and after PCI $(p=0.025)$ respectively. As all the demographic and clinical characteristics were almost similar between unfavorable and favorable outcome groups and distribution of biochemical parameters, medications used and types of stent used were also no different between the groups, the adverse outcome resulted could be attributed to abnormally high periprocedural serum fibrinogen. Various studies ${ }^{7,11}$ have shown that patients with baseline plasma fibrinogen level more than $350 \mathrm{mg} / \mathrm{dL}$ during follow up had more restenosis and adverse events when compared to patients with plasma fibrinogen level below $350 \mathrm{mg} / \mathrm{dL}$ bearing consistency with the findings of the present study.

Kvitha et al. ${ }^{12}$ showed that plasma fibrinogen levels at baseline, 24 hours and 72 hours after PCI all were signiûcantly raised in patients who developed repeat angina and myocardial infarction after the stenting $(\mathrm{p}=$ $0.003, p=0.008$ and $p=0.012$ respectively) compared to those who did not develop any of the adverse events. Based on this finding they concluded that plasma ûbrinogen plays a signiûcant role in the development of adverse events following stenting and it can be used as a marker for predicting long-term outcome of PCI. Otsuka and colleagues ${ }^{11}$ in a similar study in Japan compared 6- 12-month outcomes of patients grouped into tertiles based on baseline fibrinogen levels (the clinical and angiographic characteristics were almost comparable at baseline). An increasing rate of restenosis was observed from the lowest to the highest tertiles $(18.6,23.9,38.1 \%$ respectively, $\mathrm{p}<$ $0.001)$. Multivariate analysis revealed that high levels of fibrinogen and stent length were independent predictors for restenosis $(p<0.001$ and $p=0.034$ respectively). Likewise Braim ${ }^{13}$ measured baseline concentrations of acute-phase reactants, such as CRP, interleukin-6 (IL-6), lipoprotein (a) (Lp (a)), and ûbrinogen of 600 patients immediately before PCI and collected follow up data after 8 months. Major adverse clinical events (MACE) were significantly higher in patients who had elevated CRP, Lp(a) and ûbrinogen and also advocated that elevated serum fibrinogen is a strong predictor of longer-term ischemic cardiac events after PCI even stronger than the newly invented P2Y12 platelet reactivity measurements. However, Pascalle et al. ${ }^{5}$ in the GENDER project demonstrated that there is no relationship between preprocedural fibrinogen level and clinical restenosis at followup among patients with coronary stent deployment contrasting with the findings of the present study.

In the present study, plasma fibrinogen level was increased following stenting and the level remained elevated when measured at 72 hours post-PCI. This may be due to disruption of the vascular wall by stenting which may attract various inflammatory cells resulting in cytokine production, which in turn, leads to increased production of acute phase proteins including fibrinogen. ${ }^{14}$ Fibrinogen is an acute phase reactant protein and a pro inflammatory marker which plays an important role in platelet aggregation, increases plasma viscosity, causes the release of vasoconstrictor mediators and growth factors and also leads to fibrin deposits. ${ }^{5}$ 
As plasma fibrinogen level increased after stenting was irrespective of types of stent used (either bare metal or drug eluting stents), it indicates that the stenting procedure itself induced an inflammatory response. Restenosis after coronary stenting is thought to be mainly due to neointimal proliferation. The migration and proliferation of smooth muscle cells, induced by the production and release of growth factors, cytokines and extracellular matrix synthesis, result in neointimal proliferation and eventually represents the restenosis. ${ }^{15}$ Stent implantation induces a vascular inflammatory response which also contributes to restenosis. ${ }^{15}$ Increased fibrinogen causes alterations in fibrin clot structure and this is shown to impair fibrinolysis and increase the risk of cardiovascular events following stent procedure including stent thrombosis.

Fibrinogen may be considered a risk factor for restenosis because fibrin degradation products stimulate smooth muscle cell outgrowth which is seen in neointimal proliferation leading to restenosis. ${ }^{7}$ For example, fibrinogen can promote endothelial-cell migration and extracellular accumulation of low-density lipoproteins. Fibrinogen can promote platelet aggregation by interacting with $\mathrm{GP} \mathrm{IIb} /$ IIIa receptors on the platelet membrane. In addition, an elevated level of plasma fibrinogen increases blood viscosity, ${ }^{9}$ which causes impaired microcirculatory flow, endothelial shear-stress damage, and predisposition to thrombosis. ${ }^{16}$

However, there are certain limitations in this study which deserve mention. In the present study, only incidence of adverse events during six month follow up was assessed. Angiographic follow up was not done and hence percentage of restenosis was not determined.

Summarizing the findings it is evident that high periprocedural plasma fibrinogen levels can be used to assess the risk of developing adverse cardiac events following PCI.

\section{Conclusion:}

From the findings of the study it can be concluded that the risk of developing unfavorable outcome in patients with high peri-PCI serum fibrinogen levels is higher than those who have low serum fibrinogen levels. As demographic, clinical and biochemical characteristics of the patients of unfavorable and favorable outcome groups were almost similar and medications used and types of stent used were almost alike between the groups, the adverse outcomes observed could be attributed to high periprocedural serum fibrinogen.

\section{References:}

1. Gomma AH, Hirschfield GM, Gallimore JR, Lowe GDO, Pepys MB, Fox KM. 'Preprocedural inflammatory markers do not predict restenosis after successful coronary stenting', Am Heart $J$, vol. 2004;147:1071-77.

2. Kursaklioglu H, Iyisoy A, Amasyali B, et al. 'Spironolactone does not prevent restenosis after coronary stenting in humans', Ann Acad Med, 2004;33:769-74.

3. Liuzzo G, Biasucci LM, Gallimore JR, Grillo RL, Rebuzzi AG, Pepys MB, Maseri A.'The prognostic value of C-reactive protein and serum amyloid a protein in severe unstable angina,' N Engl J Med, 1994;331(7):417-24.

4. Biasucci LM, Liuzzo G, Grillo RL, Caligiuri G, Rebuzzi AG, Buffon A, et al. 'Elevated levels of C-reactive protein at discharge in patients with unstable angina predict recurrent instability,' Circulation, 1999;99(7):855-60.

5. Pascalle SM, Jamal SR, Aeilko HZ, et al. '455 G/A polymorphism and preprocedural plasma levels of fibrinogen show no association with the risk of clinical restenosis in patients with coronary stent placement', Thromb Haemost, 2005;93:564-69.

6. Smith EB. 'Fibrinogen, fibrin and fibrin degradation products in relation to atherosclerosis', Clin Haematol, 1986;15: 355-70.

7. Rahel BM, Visseren FLJ, Suttorp M, et al. 'Preprocedural serum levels of acute-phase reactants and prognosis after percutaneous coronary intervention', Cardiovasc Res, 2003;60:136-40.

8. Ernst, E. 'The role of fibrinogen as a cardiovascular risk factor,'Ann Intern Med, 1993;118:956-63.

9. Corrado E, Novo S. 'Role of inflammation and infection in vascular disease’, Acta Chir Belg, 2005;105:567-79.

10. Ernst E, Koenig W, Lowe GDO, Meade TW; eds. Fibrinogen, A "New" Cardiovascular Risk Factor. Oxford: Blackwell; 1992.

11. Otsuka M, Hayashi YUeda H, Imazu M, Kohno N. 'Predictive value of preprocedural fibrinogen concerning coronary stenting, Atherosclerosis, 2002;164:371-78.

12. Kavitha, S., Sridhar, MG., Satheesh, S. Periprocedural plasma fibrinogen levels and coronary stent outcome,' Indian heart journal, 2015;67:440-43.

13. Braim MR, Frank JV, Maarten-Jan S, Thijs HWP, Johannes CK, Bartelt MJ, Paul K B, Rob JAD. 'Preprocedural serum levels of acute-phase reactants and prognosis after percutaneous coronary intervention', Cardiovascular Research, 2003;60:136-40.

14. Castell JV, Gomez-Lechon MJ, David M, et al. 'Acute-phase response of human hepatocytes: regulation of acute-phase protein synthesis by interleukin-6', Hepatology, 1990; $12: 1179-86$.

15. Cura M, Sprague E. 'Bare-stent technology and its utilization in the treatment of atherosclerotic obstructive disease', Vasc Dis Manag, 2010;7:95-102.

16. Shi Y, Wu Y, Bian C, Zhang W, Yang J, Xu G. 'Predictive value of plasma fibrinogen levels in patients admitted for acute coronary syndrome', Tex Heart Inst J, 2010;37:178-83. 